\title{
Os Contratos De Arrendamento De Imóveis Rurais Para A Exploração De Energia Eólica Por Empresas De Capital Estrangeiro E A Imposição De Normas Que Afetam A Ordem Econômica Nacional
}

\author{
Bruno Bastos de Oliveira * \\ Universiadade de Marília, Programa de Pós-Graduação em Direito, Marília-SP, Brasil. \\ iD https://orcid.org/0000-0002-4563-6366 \\ Fellipe Vilas Bôas Fraga \\ Universiadade de Marília, Programa de Pós-Graduação em Direito, Marília-SP, Brasil.
}

iD https://orcid.org/0000-0002-2907-8974

\begin{abstract}
Resumo: O presente artigo tem por escopo analisar as questões que envolvem exploração de energia eólica em imóveis rurais por empresas com percentual de capital estrangeiro, cujos contratos sejam celebrados sob a espécie de arrendamento. Como grande parte das empresas que investem em energia eólica no Brasil possuem parte do capital estrangeiro, as determinações legais acarretam a aplicação de normas que tornam a exploração dessa tecnologia limpa mais dispendiosa, muitas vezes afastando investimentos e até inviabilizando esse ramo do setor energético, consequentemente afetando o desenvolvimento nacional sustentável, a ordem econômica social e a preservação do meio ambiente. Buscar-se-á analisar a necessidade de modificação das regras para o contrato de arrendamento de imóveis rurais para a exploração de energia eólica por parte de pessoas jurídicas que tenham capital estrangeiro. Como metodologia, será utilizado o método dedutivo, por meio de pesquisa bibliográfica e legislativa. Conclui-se pela necessidade de modificação no entendimento normativo, de forma que nos contratos para arrendamento de imóveis rurais para exploração de energia eólica, quer sejam firmados por empresas com capital exclusivamente nacional ou não, não sejam impostas as regras do art. 23 da Lei 8.629/93.
\end{abstract}

Palavras-chave: Tecnologias limpas. Energia eólica. Arrendamento. Capital estrangeiro. Desenvolvimento Sustentável.

* Doutor em Direitos Humanos e Desenvolvimento pela UFPB. Professor do PPGD UNIMAR - Mestrado e Doutorado... E-mail: bbastos.adv@gmail.com

** Mestrando pelo Programa de Pós Graduação em Direito da Universidade de Marília - UNIMAR. Email: fellipevilasboas@gmail.com

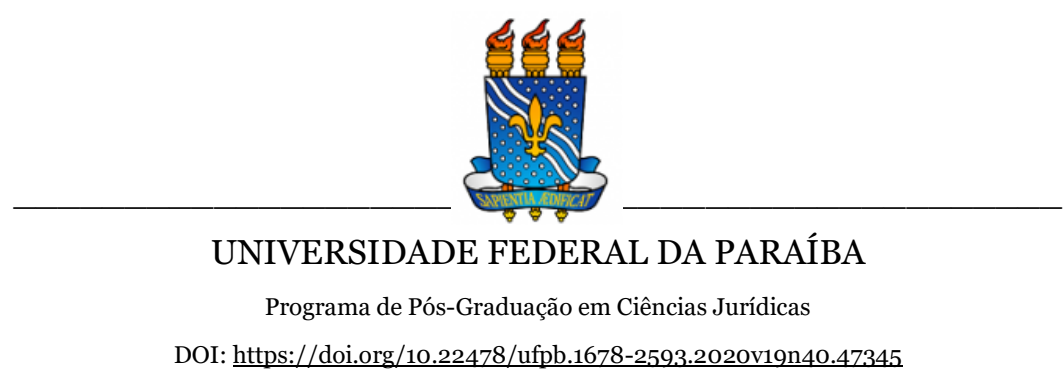




\title{
Os Contratos De Arrendamento De Imóveis Rurais Para A Exploração De Energia Eólica Por Empresas De Capital Estrangeiro E A Imposição De Normas Que Afetam A Ordem Econômica Nacional
}

\author{
Bruno Bastos de Oliveira ${ }^{1}$
}

Fellipe Vilas Bôas Fraga

\section{INTRODUÇÃO}

O ser humano, atrelado a paradigmas e padrões tecnológicos que direcionam as ações sociais, vem contribuindo com a degradação do meio ambiente em que vive, representando nada menos do que as opções políticas econômicas e sociais ao longo da história. Ocorre que, diante da insustentabilidade do atual modo de vida poluente, destrutivo e predatório, nas últimas décadas a humanidade vem se deparando como a necessidade de adequação dessas opções à preservação do meio ambiente.

Diante disso, tentando reverter os impactos ambientais que afetam a saúde das pessoas, a fauna, a flora e a atmosfera terrestre, fatores que acabam contribuindo para o aquecimento global e outras mazelas, os atores - econômicos, políticos e sociais - repensam estratégias de agir, produzir e consumir bens e serviços, projetando um desenvolvimento sustentável, sem afetar o meio ambiente necessário para a sobrevivência humana.

\footnotetext{
${ }^{1}$ Bolsista PNPD na Universidade de Marília UNIMAR
} 
Os Contratos De Arrendamento De Imóveis Rurais Para A Exploração De...

Nesse contexto, a energia elétrica, indispensável que é para a sociedade contemporânea, também precisa ser produzida por meio da utilização de um processo mais racional. É nessa conjuntura que entra em cena a energia eólica, sempre atendo-se ao fato de que para ser efetivamente limpa, não é suficiente a emissão de menores índices poluentes, mas também se relacionando com questões sociais e ambientais correlatas.

A utilização da energia eólica, que provém da captação dos ventos e sua transformação em energia, atualmente vem crescendo consideravelmente no país. A viabilidade de sua exploração se dá por intermédio da celebração de contratos que, na maioria das vezes, são de arrendamento de imóveis rurais, que devem ser levados à Serventia Extrajudicial do registro de imóveis da comarca onde estiver localizado, para fins de publicidade, segurança jurídica e eficácia perante terceiros.

Ocorre que boa parte das empresas que investem em energia eólica no Brasil não possuem o capital necessário, precisando de investimento estrangeiro direto, havendo no ordenamento jurídico pátrio determinação legal que torna a exploração da energia eólica por parte de estrangeiros mais dispendiosa, o que pode desestimular os investimentos nesse setor, afetando o desenvolvimento nacional, a busca do pleno emprego e o meio ambiente ecologicamente equilibrado.

Assim, o que se propõe ao longo do trabalho é demonstrar que a aplicação dessa norma mais dificultosa vai contra o desenvolvimento nacional sustentável, o meio ambiente e o cenário atual de desburocratização, carecendo de revisão legislativa.

Como metodologia, foi feita a opção pelo método dedutivo, com pesquisa qualitativa do tipo exploratório por meio de estudo bibliográfico, analítico e documental. 


\title{
2 TECNOLOGIAS LIMPAS
}

A forma de agir cada vez mais predatória e poluidora da humanidade transformou negativamente o planeta, especialmente no período posterior à Revolução Industrial. Esse processo veio a ocasionar, dentre tantos outros males, extinção em massa de espécies em uma velocidade que o planeta jamais experimentou, na desertificação de locais em proporções estratosféricas devido à retirada da flora nativa para o plantio, bem como na poluição do meio ambiente para poder produzir a tão desejada energia elétrica, afetando a atmosfera terrestre, protetora da vida na Terra.

Thiago Flores dos Santos e Ana Carla Pinheiro Freitas lembram que:

\begin{abstract}
A partir da constatação da significativa degradação do meio ambiente ocorrida no Século XX, inicialmente nos países da Europa, torna-se corrente nos discursos políticos e na agenda empresarial global o conceito de desenvolvimento sustentável, surgido a partir do Relatório Brundtland (documento intitulado "Nosso futuro comum"), de 1987, produzido pela Organização das Nações Unidas - ONU. É entendido como o processo que satisfaz as necessidades presentes sem comprometer a capacidade das gerações futuras de suprir suas próprias necessidades, sendo estabelecida a necessidade de serem adotadas medidas que reduzam a chamada pegada ecológica decorrente das atividades humanas e promovam a justiça social, mantendo-se a rentabilidade necessária ao crescimento econômico. (SANTOS; FREITAS, 2017, p. 2)
\end{abstract}

Nesse contexto, destaca-se a necessidade de reconhecer que o direito ao meio ambiente ecologicamente equilibrado se insere nos propósitos da Declaração dos Direitos Humanos pela Assembleia Geral da ONU (LASBIK; GOMES, 2018, p. 7), o que reforça a necessidade de se buscar a implementação de tecnologias limpas.

Tecnologia limpa pode ser definida como toda aquela cujo processo e utilização são voltados ao desenvolvimento sustentável e à diminuição dos impactos ambientais e, sempre que possível, a não poluir, estando em contraposição com a forma de produção que vem sendo utilizada desde a revolução industrial até os tempos atuais, que causam danos ambientais por meio de fontes poluentes e quase 
Os Contratos De Arrendamento De Imóveis Rurais Para A Exploração De...

sempre não renováveis como, por exemplo, o carvão mineral e vegetal, o petróleo e o gás natural. Aqui não se afirma que as fontes renováveis não são poluentes, pelo contrário, porém não há como reconhecer os mesmos impactos ambientais decorrentes dessas em relação as não renováveis.

Essas tecnologias mais limpas representam, a depender de como são concebidas, planejadas e executadas, avanço racional da humanidade no caminho para a conscientização quanto à preservação do meio ambiente, promovendo a utilização dos recursos de forma sustentável, havendo, portanto, o emprego da tecnologia sempre com o objetivo de não afetar o meio ambiente e a atmosfera terrestre ou, quando afetar, fazer com que as consequências sejam mínimas e reversíveis.

A urgência de mudança de pensamento para com a exploração dos recursos naturais de nosso planeta, cujos impactos ambientais negativos já vêm se fazendo sentir há décadas, baseia-se na mais pura e objetiva necessidade humana, que é a sobrevivência. Nesse sentido, conforme apontam Ferreira e Gomes (2017, p. 629), é possível afirmar que o meio ambiente, ao ser tratado como norma fundamental, se relaciona com o próprio direito à vida.

Como instrumento de auxílio ao desenvolvimento sustentável, as tecnologias mais limpas têm como princípio basilar a prevenção pela não poluição, sendo que a própria Carta Magna, em seu artigo 225, preconiza que todos têm direito ao meio ambiente ecologicamente equilibrado ${ }^{2}$. Nesse contexto, há que se ponderar efetivamente que até mesmo as energias limpas possuem impactos poluidores, o que deve ser sopesado na prática, uma vez que, por exemplo, as energias hidráulicas não podem ser consideradas energias limpas, dado ao grau de impacto ambiental decorrente.

2 Art. 225. Todos têm direito ao meio ambiente ecologicamente equilibrado, bem de uso comum do povo e essencial à sadia qualidade de vida, impondo-se ao Poder Público e à coletividade o dever de defendê-lo e preservá-lo para as presentes e futuras gerações. 
Conforme destacam Fernando Joaquim Ferreira Maia e Rafaela Patrícia Inocêncio da Silva, a proteção ao meio ambiente é parte fundamental na concretização do Estado Social e Democrático de Direito, sendo primordial para que se alcance o desenvolvimento econômico e social. Afirmam os autores que "a cultura do cuidar dirigido ao ambiente não é só voltada ao desenvolvimento; zelar pelo lugar em que se vive é, antes de tudo, algo essencial à continuidade da vida humana" (MAIA; SILVA, 2018, p. 3).

Partindo do pressuposto de que é plenamente possível alterar a direção da forma de captação e exploração das principais tecnologias energéticas, numa das múltiplas e mais variadas facetas das tecnologias limpas têm-se as de potencial energético.

\subsection{Tecnologias Energéticas Limpas}

Energia limpa é toda forma de produção de eletricidade originada pela utilização de fontes renováveis, cujo processo e exploração sejam efetuados sem ou com a menor forma possível de poluição ou impacto ambiental.

Segundo sustentam Maidana e Boggi (2009, p. 185-186):

\footnotetext{
Consideradas as expectativas de aumento da população e de crescimento econômico, que demandarão uma quantidade de energia cada vez maior, conclui-se que a descarbonização da economia, mediante a utilização das chamadas fontes energéticas limpas, não representa apenas $o$ anseio de integrantes dos movimentos ambientalistas de há duas ou três décadas atrás, mas é o único caminho viável para o desenvolvimento sustentável.
}

Nos dias atuais, a problematização quanto à possibilidade de utilização dessas tecnologias energéticas mais limpas em escala industrial recai sobre o custo ainda demasiadamente alto para sua operacionalização e distribuição se comparado à utilização das energias sujas. 
Os Contratos De Arrendamento De Imóveis Rurais Para A Exploração De...

Importante mencionar que, pelo processo atualmente utilizado no que concerne ao cenário nacional, as energias nucleares e hidráulicas não podem ser consideradas energias limpas.

Isto porque, quanto à energia nuclear, além do enorme risco de contaminação ambiental, como ocorreu no acidente nuclear de Chernobyl, as águas quentes que da usina saem, não muito raro, podem ocasionar poluição térmica, prejudicando fauna e flora.

Já quanto à energia hidráulica, seus impactos ambientais podem ser titânicos, causando o deslocamento da população, mudança de paisagem e aniquilação de ecossistemas, afetando, inclusive, direitos fundamentais de comunidades tradicionais brasileiras como as dos quilombolas, assim como as dos índios, como bem observa Feijó (2014, p. 67):

O governo brasileiro e as empresas não só desrespeitam o
dever de consultar as comunidades impactadas, nos
moldes da Convenção 169/OIT, como excluem as
comunidades das estratégias de manejo ambiental,
prevenção e reparação de áreas degradadas, restando as
populações indígenas e tribais marginalizadas, sofrendo os
impactos dos empreendimentos econômicos em suas
terras, sem, contudo, se beneficiar dos planos de
regeneração da área.

Dentre as tecnologias energéticas limpas e renováveis mais importantes da atualidade estão as formas de captação e exploração de energia solar e eólica que, em comparação com outras, contribuem de forma mais eficiente com a preservação do meio ambiente ecologicamente equilibrado para a atual e futuras gerações, assim como para o desenvolvimento econômico sustentável e com o fim do deslocamento forçado de populações para exploração de fontes energéticas.

Mais uma vez, há que se ressaltar que existe literatura densa acerca dos impactos ambientais potenciais da indústria de geração eólica. Amanda Alves Araújo e Geraldo Jorge Barbosa de Moura afirmam que "embora a energia advinda de fontes eólicas apresente bastantes benefícios quando comparadas a outros meios de se obter 
energia, há uma variedade de impactos negativos proporcionados com a instalação de parques eólicos [...]" (ARAÚJO; MOURA, 2017, p. 217). Os impactos à fauna, ao meio físico e até mesmo aos aspectos sociais deve ser objeto de ponderação razoável, uma vez que, dentro de um contexto mais amplo, existe a necessidade de serem adotadas os meios menos poluentes possíveis.

\subsection{A Regulamentação das Tecnologias Energéticas Limpas e o Panorama Nacional}

Coração de todo e qualquer ato ou fato que possa reverberar na esfera ambiental, é através do sentido de sustentabilidade e equilíbrio ecológico e do meio ambiente, preconizado pela Constituição Federal de 19883 , que se baseiam as tecnologias de exploração de potencial energético mais limpas.

Norma verde e recepcionada pela Constituição Federal, a Lei Federal $\mathrm{n}^{0}$ 6.938, de 31 de agosto de 1981 (BRASIL, 1981, on-line), dispõe sobre a Política Nacional do Meio Ambiente, cujo artigo segundo menciona objetivos e prescreve que um de seus princípios é o incentivo à pesquisa de tecnologias limpas.

Nota-se que a preocupação em incentivar o desenvolvimento de tecnologias limpas com o intuito de manter o desenvolvimento sustentável e o meio ambiente ecologicamente equilibrado, direito fundamental, intrinsecamente ligado à dignidade da pessoa humana $\mathrm{e}$ ao direito à vida, vem de antes da Constituição da República Federativa do Brasil de 1988.

Seguindo esse caminho, em 8 de janeiro de 1997, a Lei Federal no 9.433 (BRASIL, 1997, on-line) instituiu a Política Nacional de Recursos Hídricos, dispondo no parágrafo segundo do artigo 12 que a outorga e a utilização de recursos hídricos para fins de geração de energia elétrica estarão subordinadas ao Plano Nacional de Recursos

3 Menção à Constituição da República Federativa do Brasil de 1988, acerca do meio ambiente. 
Os Contratos De Arrendamento De Imóveis Rurais Para A Exploração De...

Hídricos. Salienta-se que atualmente a energia provinda das usinas hidrelétricas ainda é responsável por mais da metade da geração da energia utilizada no Brasil, tendo sido implementada no país sob o adjetivo de ser uma forma de captação de energia limpa e de baixo custo (Governo do Brasil, 2011, on-line) ${ }^{4}$. Conforme informa Prolo et al. (2018, on-line), a geração hidráulica representa atualmente 77,5\% da matriz energética brasileira que compõe o Sistema Interligado Nacional.

Entretanto, com o passar dos anos, provou-se que a energia hidrelétrica não é barata, muito menos limpa, contribuindo, inclusive, para com a emissão de gases de efeito estufa, o que afeta na mudança climática, além de afetar o curso normal dos rios e obrigar o deslocamento forçado de pessoas dos locais onde residiam (UFJF, 2016, on-line)5.

Nessa conjectura, em 9 de dezembro de 2009 entra em vigor a Lei Federal $n^{0} 12.114$ (BRASIL, 2009, on-line), que cria o Fundo Nacional sobre Mudança do Clima e tem a finalidade de criar subterfúgios para mitigar a mudança climática e desenvolver novas práticas de energias limpas, auxiliando no combate à mudança climática.

No mesmo ano de 2009, em 29 de dezembro, a Lei Federal $n^{0}$ 12.187 (BRASIL, 2009, on-line) institui a Política Nacional sobre Mudança do Clima, trazendo como instrumento medidas para estimular o desenvolvimento de tecnologias que contribuam para a redução de emissões de gases de efeito estufa.

Referida lei tem por objetivo estimular o desenvolvimento de tecnologias, incluindo-se as energéticas, que auxiliem na redução de emissão de gases de efeito estufa, que afetam a mudança climática e o meio ambiente, prevendo em seu texto que por Decreto do Poder Executivo se estabelecerá, dentre outras coisas, planos específicos para

4 Informação publicada em 13/12/2011, cuja última modificação foi em 23/12/2017, segundo informações do Governo do Brasil.

5 Pesquisa realizada em 28/01/2016, segundo informações da UFJF. 
mitigação e adaptação às mudanças climáticas com a finalidade de consolidar uma economia de baixo consumo de carbono, na geração e distribuição de energia elétrica.

Esse Decreto foi o de $\mathrm{n}^{0} 7.390$ de 9 de dezembro de 2010 (BRASIL, 2010, on-line), tendo sido revogado em 22 de novembro de 2018 pelo Decreto 9.578 (BRASIL, 2018, on-line), que Consolida atos normativos editados pelo Poder Executivo federal que dispõem sobre o Fundo Nacional sobre Mudança do Clima e a Política Nacional sobre Mudança do Clima e, conforme o artigo 17, considerando o Plano Decenal de Expansão de Energia como plano de ação para prevenção e controle do desmatamento nos biomas e planos setoriais de mitigação e de adaptação às mudanças climáticas.

Em 2 de agosto de 2010, a Lei Federal $\mathrm{n}^{0} 12.305$ (BRASIL, 2010, on-line) instituiu a Política Nacional de Resíduos Sólidos, prevendo em seu texto o estímulo ao consumo sustentável como objetivo.

Dessa forma, todas as medidas normativas tomadas em prol do meio ambiente ecologicamente sustentável caminham no sentido evolutivo de uma substituição dos métodos que poluem para tecnologias mais limpas e sustentáveis ecologicamente, que façam por manter a atmosfera terrestre viável à vida humana para as futuras gerações, estando o desenvolvimento e a exploração da energia eólica ligada a esse meio, por ser uma energia mais limpa, renovável e sustentável.

\subsection{O Projeto de Lei $n^{0} 3.889$ de 2012}

Em 22 de maio de 2002, a então Deputada Federal pelo Estado do Rio de Janeiro, do partido político PCdoB, senhora Jandira Feghali, apresentou o Projeto de Lei da Câmara dos Deputados no ${ }^{0} 3.899$.

Tal projeto de lei justifica-se na necessidade de uso dos recursos naturais com o equilíbrio ambiental de forma economicamente viável e socialmente justa, objetivando, também, garantir o direito das gerações futuras quanto ao uso de tais recursos. 
Os Contratos De Arrendamento De Imóveis Rurais Para A Exploração De...

Dentre os pontos mais relevantes desse projeto de lei, têm-se a instituição da Política Nacional de Estímulo à Produção e ao Consumo Sustentáveis, voltada para o incentivo da adoção de práticas de consumo e produção ecológica e economicamente sustentáveis.

Ademais, o projeto legislativo elenca como princípios da Política Nacional de Estímulo à Produção e ao Consumo Sustentáveis o desenvolvimento sustentável e a ecoeficiência, tratando, em seu artigo quarto, como diretrizes a equidade ao consumo e o acesso à energia, bem como a promoção da inovação e o acesso à tecnologia.

Outrossim, trata como objetivos da Política Nacional de Estímulo à Produção e ao Consumo Sustentáveis incentivar o desenvolvimento de sistemas de gestão ambiental e empresarial voltados para a melhoria dos processos produtivos e a adoção, o desenvolvimento e o aprimoramento de tecnologias limpas como forma de minimizar impactos ambientais e promover o incremento de energia renovável, em especial de fontes alternativas na matriz energética brasileira.

Destarte, a transformação desse projeto em lei se constituirá em um efetivo instrumento de auxílio e de compatibilização no desenvolvimento social, tecnológico e econômico de forma correta, respeitando-se o meio ambiente no uso de recursos naturais, contribuindo-se no combate à poluição.

\subsection{Da Matriz Energética Brasileira e da Necessidade do Uso de Novas Tecnologias}

No que concerne à geração de energia elétrica, conforme foi possível observar anteriormente, o Brasil sempre optou por priorizar a construção de hidrelétricas. Isso se deu pelo fato de a energia hidrelétrica ser fonte renovável, fornecer certa flexibilidade operacional e, até mesmo, pela grande quantidade de rios no Brasil, além do suposto baixo custo para instalação e exploração se 
comparado aos gastos necessários para a efetiva utilização de outros recursos energéticos, bem como pela ideia de que a poluição seria menor, quando não é.

Segundo dispõe Fearnside e Millikan (2012, p. 47):

As hidrelétricas têm enormes impactos, muitos dos quais não são amplamente conhecidos pelo público em geral, não são considerados no planejamento e na viabilidade econômica, ou não são devidamente avaliados no atual sistema de licenciamento ambiental no Brasil e em muitos outros países.

Por consequência desse investimento nas hidrelétricas, a primeira regulamentação do setor energético foi o Decreto $\mathrm{n}^{0} 24.643$, de 10 de julho de 1934 (BRASIL, 1934, on-line), o denominado Código de Águas, objetivando impor medidas para o aproveitamento racional da energia hidráulica.

Contudo, a crise hídrica do início do século XXI revelou a situação de vulnerabilidade e dependência do país nessa fonte de captação de energia elétrica.

Por derradeiro, em consonância com as palavras de Célio Bermann, assessor do Ministério de Minas e Energia durante os dois primeiros anos do governo Lula (2010, on-line), as três maiores hidrelétricas construídas na região amazônica, até agora, emitem gases de efeito estufa mais ou na mesma proporção que usinas a carvão mineral.

Esse fato, somando-se às pressões na esfera internacional para a implantação de um sistema de captação de energia elétrica baseado em tecnologias mais limpas, com menor impacto ambiental, em respeito ao Protocolo de Quioto, tornou necessário o uso de medidas inovadoras no intuito de consolidar outras fontes renováveis passíveis de exploração para geração de energia elétrica, fazendo com que o Brasil viesse a buscar pela implementação de novos modelos como os de energia solar, biomassa e eólica.

Assim, em 6 de agosto de 1997, entrou em vigor a Lei Federal $\mathrm{n}^{0} 9.478$ (BRASIL, 1997, on-line), que dispõe sobre a política 
Os Contratos De Arrendamento De Imóveis Rurais Para A Exploração De...

energética nacional e institui o Conselho Nacional de Política Energética e a Agência Nacional, vinculados à Presidência da República.

Diante da situação de gravidade em relação à crise hídrica e dos impactos ambientais causados pela instalação e exploração das usinas hidrelétricas nacionais, em 5 de julho de 2001, a Câmara de Gestão da Crise de Energia Elétrica editou a Resolução no 24 (BRASIL, 2001, online), criando o Programa Emergencial de Energia Eólica PROEÓLICA. Essa normativa, para promoção da energia eólica no cenário nacional, tem como objetivos viabilizar efetivamente a exploração e o aproveitamento da energia eólica.

Por sua vez, com a Lei Federal $\mathrm{n}^{0}$ 10.438, de 26 de abril de 2002 (BRASIL, 2002, on-line), com as alterações dadas pelas Leis Federais $\mathrm{n}^{\mathrm{o}}$ 10.762, de 11 de novembro de 2003 (BRASIL, 2003, on-line) e 11.075, de 30 de dezembro de 2004 (BRASIL, 2004, on-line), ficou instituído o Programa de Incentivo às Fontes Alternativas de Energia Elétrica - Proinfa -, cujo artigo terceiro menciona o objetivo de aumentar a participação da energia elétrica produzida por empreendimentos de Produtores Independentes Autônomos, concebidos com base em fontes eólicas, pequenas centrais hidrelétricas e biomassa, no Sistema Elétrico Interligado Nacional ${ }^{6}$. A alteração dada pela Lei 12.783, de 11 de janeiro de 2013 (BRASIL, 2013, on-line), incluiu o artigo 13, que criou a Conta de Desenvolvimento Energético - CDE -, com o objetivo de promoção da competitividade de produção de energia limpa.

Nesse contexto, é possível observar que o Programa de Incentivo às Fontes Alternativas de Energia Elétrica - Proinfa -, foi arrojado, objetivando a diversificação da matriz energética, concedendo garantias de compra de energia em contratos de 20 anos

\footnotetext{
6 A Lei Federal $n^{0}$ 10.438, de 26 de abril de 2002, dispõe sobre a expansão da oferta de energia elétrica emergencial, recomposição tarifária extraordinária, cria o Programa de Incentivo às Fontes Alternativas de Energia Elétrica (Proinfa), a Conta de Desenvolvimento Energético (CDE), dispõe sobre a universalização do serviço público de energia elétrica.
} 
e oferecendo financiamentos do BNDES para implantação de tais projetos, auxiliando a impulsionar o desenvolvimento e exploração do setor de produção de energia limpa.

\section{ENERGIA EÓLICA E O PROJETO DE LEI No 484 DE 2017}

Fonte alternativa de geração de energia elétrica, eólica é a energia captada através dos ventos, tratando-se de um processo que consiste em transformar o vento em energia elétrica útil por meio da captação por turbinas e/ou hélices fixadas em um pilar, comumente chamados de cata-ventos.

Segundo Silva e Vieira (2016, p.74), trata-se de uma energia renovável, de baixo custo de implantação e manutenção, altamente geradora de postos de trabalho, conforme explicitado, além dos baixos impactos causados.

Assim, a produção quantitativa dessa energia depende da constância e rapidez dos ventos no local, motivo pelo qual os captadores não podem ser instalados em qualquer região e, exatamente por esse motivo, antes de sua implementação é necessário realizar toda uma etapa de estudos de viabilidade no possível local de instalação.

A utilização dessa energia de produção e desenvolvimento sustentável vem crescendo cada vez mais, sendo a segunda maior fonte de energia elétrica utilizada no Brasil, abastecendo cerca de 22 milhões de residências por mês.

No cenário internacional, conforme Associação Brasileira de Energia Eólica, o Brasil ficou como $5^{\circ}$ colocado no Ranking Mundial de capacidade eólica nova onshore instalada em 2018, estando na frente de países desenvolvidos como, por exemplo, a Suécia, o Reino Unido, a França e o Canadá. (ABEEólica, 2018, on-line).

Um dos grandes motivos desse crescimento advém da desoneração fiscal, pois o Estado, no intuito de incentivar essa forma 
Os Contratos De Arrendamento De Imóveis Rurais Para A Exploração De...

de captação de energia mais limpa, vem implementando hipóteses de isenções e não incidências tributárias na geração de energias limpas.

São exemplos dessa política a Lei Federal $\mathrm{n}^{0}$ 11.488, de 15 de junho de 2007 (BRASIL, 2007, on-line), que cria o Regime Especial de Incentivos para o Desenvolvimento da Infra-Estrutura - REIDI e desonera o PIS/COFINS incidente na importação direta e na compra nacional de máquinas, aparelhos e equipamentos incorporados em obras de infraestrutura destinadas ao ativo imobilizado; e a Lei Federal $\mathrm{n}^{0}$ 13.097, de 19 de janeiro de 2015 (BRASIL, 2015, on-line), que reduz a zero as alíquotas da Contribuição para o PIS/PASEP, da COFINS, da Contribuição para o PIS/Pasep-Importação e da Cofins-Importação incidentes sobre a receita de vendas e na importação de partes utilizadas em aerogeradores.

Alguns estados, objetivando a implementação das tecnologias para a captação das energias renováveis e mais limpas, vem publicando suas próprias normas de incentivo, como é o caso do estado de São Paulo, cujo Decreto $n^{0}$ 58.107, de 5 de junho de 2012 (SÃO PAULO, 2012, on-line), firma como um de seus principais compromissos aumentar, até 2020, a participação de 55\% para $69 \%$ de energias renováveis no consumo final de energia do estado (hidráulica, biomassa, biogás, biodiesel, etanol, solar, eólica e resíduos sólidos), oferecendo, inclusive, isenção do ICMS nas operações com diversos produtos utilizados na geração de energia eólica e solar.

Conforme apontam Gomes e Henkes (2015, p. 465):

A energia eólica é considerada hoje uma das grandes esperanças tecnológicas, contando com expectativas de diversos países como um dos meios de reduzir os impactos ambientais na geração de energia elétrica, pois é totalmente limpa e abundante, visto que os ventos apresentam-se como um recurso inesgotável, entretanto, alguns locais não possuem condições favoráveis para a implantação de aerogeradores, devido a fatores como altitude, relevo, vegetação, entre outros. 
Contudo, como toda implementação tecnológica e forma de captação de energia, é impossível dizer que a energia eólica é cem por cento limpa e que não causa nenhum impacto ambiental.

Segundo apontam Araújo e Moura (2017, p. 213-216), a instalação de parques eólicos podem causar impactos sociais, como a emissão de ruídos, impacto visual e desigualdades sócio espaciais; danos à fauna, afetando aves e morcegos, podendo até ocasionar a perda de habitat de reprodução e alimentação; bem como impactos no meio físico, como o desmatamento da vegetação, alteração da paisagem e do nível hidrostático do lençol freático.

Em que pese tais apontamentos, as eólicas são método consideravelmente limpo de captação de energia, constituindo efetivo instrumento de auxílio imprescindível à diminuição da poluição causada pelos métodos sujos de produção de energia, respeitando o desenvolvimento sustentável e o meio ambiente ecologicamente equilibrado para a atual e as futuras gerações.

Em 30 de novembro de 2017, o então Senador pelo Estado de Alagoas, senhor Fernando Collor, apresentou o Projeto de Lei $n^{0} 484$ que dispõe sobre a ampliação das atribuições institucionais relacionadas à Política Energética Nacional com o objetivo de promover o desenvolvimento da geração de energia elétrica localizada no mar territorial e zona econômica exclusiva a partir de fonte eólica (BRASIL, 2017, on-line), propondo alterações nas Leis Federais 9.074/95, 9.427/96, 9.478/97 e 10.847/04.

Como justificação, o projeto de lei do Senado aponta que o Brasil ainda mantém inexplorados determinados potenciais energéticos que permitiriam aliar mais adequadamente o desenvolvimento socioeconômico da sua população com a preservação da natureza e o uso sustentável dos recursos naturais, sendo embaraçoso afirmar que até hoje não tenha sido construído sequer um parque eólico em mares brasileiro, tendo o Brasil à sua disposição um regime de ventos em seus mares maior do que duas vezes toda a capacidade instalada de seu parque gerador de energia elétrica, ou seja, um "pré-sal eólico". (BRASIL, 2017, on-line) 
Os Contratos De Arrendamento De Imóveis Rurais Para A Exploração De...

Finalizando a justificativa, o Senador Fernando Collor menciona que:

O Brasil precisa retornar ao seu papel de protagonista internacional na agenda ambiental e energética, sagrado desde a ECO 92. Mais do que apontar culpados, precisamos apontar soluções. Urge, portanto, estabelecer marco legal para a energia eólica offshore; fonte limpa, renovável e alternativa, que auxiliará a promover bases sólidas para o desenvolvimento sustentável nacional (BRASIL, 2017, on-line).

No que diz respeito a sua tramitação, o projeto de lei foi aprovado pelo plenário e remetido à Câmara dos Deputados em data de 20/12/2018.

\section{CONTRATO DE ARRENDAMENTO DE IMÓVEIS RURAIS PARA A EXPLORAÇÃO DE ENERGIA EÓLICA}

Percebe-se que, para a exploração de energia eólica onshore, faz-se necessária a utilização do solo para a instalação dos aerogeradores. Essa instalação ocorre predominantemente em zonas rurais, em virtude do regime natural de ventos na localidade e, também, pelo fato de que a implementação de aerogeradores em zonas urbanas não seria medida efetiva devido à verticalização das construções nessas áreas, o que dificulta e diminui a circulação e captação dos ventos.

Objetivando viabilidade econômica, normalmente os empresários desse ramo não adquirem a propriedade do imóvel rural, mas arrendam o direito de utilizar parcela do solo por determinado tempo, por meio de contrato levado ao cartório de registro de imóveis para fins de publicidade, segurança jurídica e validade perante terceiros.

Saliente-se que, muitas das vezes, as empresas exploradoras dessa tecnologia a priori limpa arrendam apenas a parte específica do 
solo onde será instalado o aerogerador, possibilitando, inclusive, o uso do restante da terra pelo proprietário, em uma distância minimamente segura.

\subsection{Aspectos do Contrato de Arrendamento de Imóvel Rural}

$\mathrm{O}$ arrendamento define-se por um contrato pelo qual o proprietário, arrendador, entrega o bem ao arrendatário para que seja explorado, mediante o ajuste e pagamento de determinada quantia remuneratória. Nas palavras de Almeida e Buainain (2013, p. 326):

O arrendamento é uma relação clara, que se assemelha ao aluguel de um imóvel, à locação de um automóvel, e por meio da qual uma parte cede à outra o uso de determinado bem, móvel ou imóvel, sob determinadas condições de tempo, utilização, manutenção e remuneração.

Assim, o arrendamento de imóvel rural para fins de exploração da energia eólica passou a ser uma nova e efetiva fonte de renda para diversos proprietários dessas terras rurais, que recebem, inclusive, percentual monetário com relação à produção de energia.

Ocorre que grande parte das empresas que investem no setor de energia eólica possuem parcela de capital estrangeiro, sendo então obrigadas a respeitar regras mais dificultosas quanto à instrumentalização e procedimentalização de seus contratos, o que pode desestimular o desenvolvimento no setor, afetando a ordem econômica, a efetiva geração de emprego e a circulação de riquezas, fatores determinantes para o desenvolvimento nacional.

Isto se dá porque a legislação nacional determina que, para os contratos de arrendamento rural por estrangeiros, deve-se observar as mesmas formas do contrato de aquisição de propriedade imobiliária por estrangeiros. 
Os Contratos De Arrendamento De Imóveis Rurais Para A Exploração De...

\subsection{Regras de Arrendamento Imobiliário de Imóveis Rurais Aplicáveis aos Estrangeiros}

Nesse cenário, o contrato de arrendamento de imóvel rural deve observar as regras do direito civil. Nesse contexto, conforme observam Payão e Vita (2018, p. 220-221), "a amplitude do Direito Civil abre vistas a uma série de desafios regulatórios ante um novo modelo econômico".

Por determinação da Lei Federal no 8.629, de 25 de fevereiro de 1993 (BRASIL, 1993, on-line), os arrendamentos imobiliários por estrangeiros devem respeitar as mesmas regras para a aquisição de imóveis rurais por estrangeiros, sejam eles pessoas físicas ou jurídicas.

Observa-se no artigo 23 da mencionada lei que:

\footnotetext{
Art. 23. O estrangeiro residente no País e a pessoa jurídica autorizada a funcionar no Brasil só poderão arrendar imóvel rural na forma da Lei ${ }^{0} 5.709$, de 7 de outubro de 1971.

$\S 1^{\mathrm{o}}$ Aplicam-se ao arrendamento todos os limites, restrições e condições aplicáveis à aquisição de imóveis rurais por estrangeiro, constantes da lei referida no caput deste artigo. (BRASIL, 1993, on-line)
}

Ademais, no tocante a essa imposição legal, o artigo $8^{\circ}$ da Lei Federal n ${ }^{0}$ 5.709, de 7 de outubro de 1971, determina que "na aquisição de imóvel rural por pessoa estrangeira, física ou jurídica, é da essência do ato a escritura pública" (BRASIL, 1971, on-line).

Diante desses fatos, aludida regra deve também ser aplicada em casos de arrendamento de imóvel rural por estrangeiro, seja pessoa física ou jurídica, para a exploração de energia eólica.

Outrossim, ainda há regramento quanto à questão territorial, pois o artigo 12, da mesma Lei Federal $n^{0} 5.709$, de 7 de outubro de 1971, determina percentual máximo de área de imóvel rural que pode ser objeto de aquisição por estrangeiros, sejam eles pessoa física ou jurídica, fato que também se aplica ao arrendamento, por força do artigo 23, da Lei Federal no 8.629, de 25 de fevereiro de 1993: 
Art. 12 - A soma das áreas rurais pertencentes a pessoas estrangeiras, físicas ou jurídicas, não poderá ultrapassar a um quarto da superfície dos Municípios onde se situem, comprovada por certidão do Registro de Imóveis, com base no livro auxiliar de que trata o art. 10.

$\S 1^{\mathrm{o}}$ - As pessoas da mesma nacionalidade não poderão ser proprietárias, em cada Município, de mais de 40\% (quarenta por cento) do limite fixado neste artigo. (BRASIL, 1971, on-line)

Por oportuno, o Provimento $\mathrm{n}^{\mathrm{o}}$ 43, de 17 de abril de 2015 (BRASIL, 2015, on-line)7, do Conselho Nacional de Justiça, dispôs sobre o arrendamento de imóvel rural por estrangeiro residente ou autorizado a funcionar no Brasil, bem como por pessoa jurídica brasileira da qual participe, a qualquer título, pessoa estrangeira, física ou jurídica que resida ou tenha sede no exterior e possua a maioria do capital social, devendo ser aplicado, inclusive, nos contratos de arrendamento de imóvel rural para exploração de energia eólica, havendo participação estrangeira.

Assim, para que se possa promover o arrendamento de imóveis rurais para a exploração da energia eólica por pessoa estrangeira, física ou jurídica, deve-se observar a regra geral que, além de obrigar a realização do contrato por escritura pública, limita a possibilidade de atuação por municípios, colocando a atividade de exploração de energia eólica no mesmo contexto que os casos ordinários de arrendamento para a exploração do imóvel rural por estrangeiro.

Além do mais, para que surta a devida eficácia legal perante terceiros, com a devida segurança jurídica e eficácia, é primordial que o contrato de arrendamento de imóvel rural para exploração de energia eólica seja levado à Serventia Extrajudicial do Registro de Imóveis competente, que é a do município da localidade do imóvel. Contudo, há uma evidente desordem normativa quanto ao ato que

7 O Provimento CNJ no 43, de 17 de abril de 2015, dispõe sobre o arrendamento de imóvel rural por estrangeiro residente ou autorizado a funcionar no Brasil, bem como por pessoa jurídica brasileira da qual participe, a qualquer título, pessoa estrangeira física ou jurídica que resida ou tenha sede no exterior e possua a maioria do capital social. 
Os Contratos De Arrendamento De Imóveis Rurais Para A Exploração De...

deve ser praticado e quanto ao Serviço Extrajudicial competente para essa prática, como se verá adiante.

\subsection{Publicização do Contrato de Arrendamento de Imóvel Rural}

Analisando-se a Lei de Registros Públicos - Lei 6.015, de 31 de dezembro de 1973 (BRASIL, 1973), - é passível de se chegar à conclusão de que os contratos de arrendamento de imóveis rurais não tenham acesso ao sistema registral imobiliário, tendo acesso apenas no Registro de Títulos e Documentos, já que, tanto o rol de registros quanto o rol de averbações não contemplam tal espécie de contrato.

Porém, deve-se ter em mente que o rol de atos que podem ser levados ao registro de imóveis é taxativo, mas não exaustivo. Ademais, assevera Loureiro (2018, p. 521), que a razão de ser do Direito registral é diminuir o risco dos adquirentes de imóveis ou direitos a eles relativos, por meio de uma maior segurança jurídica no tráfico imobiliário.

A miscelânea jurídica quanto ao tema é tamanha que há divergências entre o estabelecido nas Consolidações Normativas Extrajudiciais das cinco regiões do Brasil.

Na região Sudeste, o estado de São Paulo, no item $78.3^{8}$, das Normas de Serviço dos Cartórios Extrajudiciais (SÃO PAULO, 1989, on-line), ao tratar da atividade de registro de imóveis, determina que o arrendamento é ato insuscetível de registro.

Já o artigo $622^{9}$, da Codificação dos atos normativos da Corregedoria-Geral de Justiça do Estado de Minas Gerais (MINAS

8 78.3. O protesto contra alienação de bens, o arrendamento e o comodato são atos insuscetíveis de registro, admitindo-se a averbação do protesto contra alienação de bens diante de determinação judicial expressa do juiz do processo, consubstanciada em Mandado dirigido ao Oficial do Registro de Imóveis.

9 Art. 622. No Ofício de Registro de Imóveis, além da matrícula, serão feitos:

I - o registro:

[...]

a) da escritura pública de arrendamento de imóvel rural por estrangeiro residente ou 
GERAIS, 2013, on-line) relativos aos serviços notariais e de registro, determina tanto o registro, quanto a averbação.

$\mathrm{Na}$ região Sul, o artigo $245^{10}$, da Consolidação Normativa Notarial e Registral do Estado do Rio Grande do Sul (RIO GRANDE DO SUL, 2006, on-line), expressa a obrigatoriedade do registro no Registro de Títulos e Documentos, porém, facultando o registro dos contratos de arrendamento rural no Registro de Imóveis, com efeito meramente publicista.

Na região Centro-Oeste, o artigo $814^{11}$, do Código de Normas da Corregedoria-Geral de Justiça do Mato Grosso do Sul (MATO GROSSO DO SUL, 2013, on-line), assim como o estado de São Paulo, determina a insuscetibilidade do registro.

$\mathrm{Na}$ região Norte, o artigo $832^{12}$, das Diretrizes Gerais Extrajudiciais do Estado de Rondônia (RONDÔNIA, 2015, on-line), possibilita que o contrato de arrendamento adentre no fólio real mediante averbação.

autorizado a funcionar no Brasil, bem como por pessoa jurídica brasileira da qual participe, a qualquer título, pessoa estrangeira física ou jurídica que resida ou tenha sede no exterior e possua a maioria do capital social, desde que previamente registrada no Ofício de Registro de Títulos e Documentos (Provimento da Corregedoria Nacional de Justiça ${ }^{0} 43$, de 17 de abril de 2015) (Livro $n^{0}$ 2);

[...]

II - a averbação:

[...]

u) do comodato e do arrendamento, desde que previamente registrados no Ofício de Registro de Títulos e Documentos, salvo na hipótese da alínea "al" do inciso I deste artigo.

10 Art. 245 - No Registro de Títulos e Documentos proceder-se-á ao registro:

[...]

IX - do contrato de arrendamento rural.

[...]

Art. 393 - Facultar-se-á o registro dos contratos de arrendamento rural, com efeito meramente publicista, desde que preencham os requisitos definidos na Lei $\mathrm{n}^{0} 6.015$, de 31-12-73.

11 Art. 814. São requisitos do registro no Livro 2:

[...]

$\S 3^{\circ} \mathrm{O}$ protesto contra alienação de bens, o arrendamento e o comodato, são atos insuscetíveis de registro porque não elencados no artigo 167 da Lei no ${ }^{\circ} 6.015 / 1973$.

12 Art. 832. No registro de imóveis, além da matrícula, serão feitos:

[...]

II - a averbação de:

[...]

36) contrato de arrendamento de imóveis celebrados por nacionais e estrangeiros. 
Os Contratos De Arrendamento De Imóveis Rurais Para A Exploração De...

No Nordeste, região com a maior geração de energia eólica do Brasil, esse desalinho entre um e outro estado não é diferente, sendo possível observar que no Rio Grande do Norte, o Código de Normas Extrajudiciais (RIO GRANDE DO NORTE, 2016, on-line) 13 traz em seu artigo 235 a possibilidade de transcrição do contrato de arrendamento no Registro de Títulos e Documentos, e no artigo 322, facultando a averbação, para mera publicidade.

Já na Bahia, da mesma região Nordeste, primeiro estado em geração energia eólica no país (Bahia, 2017, on-line), há uma dicotomia no Código de Normas e Procedimentos dos Serviços Notariais e de Registro (BAHIA, 2018, on-line)14, pois o artigo 860 prevê que o contrato de arrendamento é ato insuscetível de registro no Registro de Imóveis, admitindo-se a averbação apenas para efeito de publicidade, mas o artigo 1.082 faculta o registro, com efeito meramente publicista no mesmo Registro de Imóveis.

No que concerne essa análise de possibilidade ou não de que se leve o contrato de arrendamento de imóvel rural à Serventia Extrajudicial de Registro de Imóveis ou à de Registro de Títulos e Documentos, nele incluso o para a exploração de energia eólica, quer seja como ato de registro ou de averbação, o Conselho Nacional de Justiça, através do Provimento $\mathrm{n}^{\mathrm{o}}$ 60, de 10 de agosto de 2017 (BRASIL, 2017, on-line), estabeleceu diretrizes gerais para a cobrança de emolumentos sobre os contratos de exploração de energia eólica.

13 Art. 235. Além das demais hipóteses previstas em lei, será transcrito no registro de títulos e documentos o contrato de arrendamento rural.

[...]

Art. 322. Além das previsões legais específicas, averbar-se-ão, na matrícula ou no registro de transcrição, para mera publicidade:

[...]

IX - o contrato de arrendamento rural, desde que preencha os requisitos definidos na Lei 6.015/73.

14 Art. 860. O protesto contra alienação de bens, o arrendamento e o comodato são atos insuscetíveis de registro, admitindo-se que sejam averbados tão somente para efeito de publicidade, sendo a averbação do protesto contra alienação de bens em face de determinação judicial expressa.

[...]

Art 1082. É facultado o registro de contrato de arrendamento rural, com efeito meramente publicista, desde que atenda aos requisitos registrais definidos na Lei ${ }^{0}$ $6.015 / 1973$. 
Ocorre que, o artigo sétimo, do aludido Provimento ${ }^{15}$, dá a entender que o ato deve ser levado à Serventia Extrajudicial do Registro de Imóveis, quando menciona que a prorrogação do contrato deve ser averbada nos livros deste.

Salienta-se, por questões mínimas de segurança, que o contrato de arrendamento de imóvel rural para exploração de energia eólica deve ser levado ao Registro de Imóveis, pois é ato que o afeta, gerando consequências jurídicas, devendo ser dada a devida publicidade.

No que se refere a essa publicidade registral, nas palavras de Márcio Guerra Serra e Monete Hipólito Serra (2013, p.147), pelo princípio da publicidade, todos os atos inscritos no registro de imóveis tornam-se públicos e somente sua inscrição faz com que atinjam a publicidade almejada perante terceiros.

Nota-se que a prática do ato de registro ou averbação, a depender da normativa procedimental de cada estado, do contrato de arrendamento de imóvel rural para exploração e energia eólica no Registro de Imóveis competente, é necessária para a devida segurança jurídica, eficácia perante terceiros e publicidade.

Contudo, há necessidade de revisão das regras legais para viabilizar efetivamente essa forma de exploração energética que, a depender dos procedimentos mitigatórios e compensatórios adotados, beneficia o meio ambiente e impulsiona a ordem econômica nacional.

\section{CONSIDERAÇÕES FINAIS}

Assim, observa-se que, pela peculiaridade da propensão dos ventos, a exploração da energia eólica é feita em terras rurais, sendo que os contratos para a exploração de energia eólica, em sua grande

15 Art. $7^{\circ}$ Havendo a prorrogação do contrato ou futura fixação de remuneração para a fase operacional, deverá ser averbado o respectivo termo aditivo no registro de imóvel, incidindo os respectivos emolumentos sobre o valor total bruto do contrato averbado. 
Os Contratos De Arrendamento De Imóveis Rurais Para A Exploração De...

maioria, são firmados sobre a espécie de arrendamento de imóvel rural.

Grande parte das empresas que investem na exploração da energia eólica no Brasil tem, ao menos, parcela de capital estrangeiro. O artigo 23 da Lei Federal no 8.629/93 determinou a aplicação da Lei Federal $\mathrm{n}^{0} 5 \cdot 709 / 71$ aos arrendamentos de imóveis rurais por estrangeiro ou pessoa jurídica autorizada a funcionar no Brasil.

Tal lei determina que é da essência do ato a escritura pública e que devem ser respeitados limites territoriais e essa normativa cria barreiras que podem inviabilizar a exploração da energia eólica no país, que pode ser fonte geradora de emprego, da circulação de riquezas, bem como instrumento de auxílio ao meio ambiente ecologicamente equilibrado para a atual e futuras gerações.

Sobrepondo todas as leis e demais atos de caráter normativo com a Constituição Federal, há de se considerar que essas barreiras, que dificultam a implementação da tecnologia a priori limpa de geração de energia eólica do Brasil, desrespeitam diretamente os preceitos da ordem econômica e da proteção do meio ambiente.

A produção de energia eólica contribui para o meio ambiente ecologicamente equilibrado, quando torna a matriz energética nacional cada vez menos dependente da energia das hidrelétricas, que poluem muito, alagam regiões, devastam ecossistemas, promovem o deslocamento compulsório da população e contribuem para a emissão de gases de efeito estufa.

Por todo o exposto, a implementação da energia eólica, que também possui impacto ambiental considerado, porém passíveis de serem mitigados, deve merecer tratamento diferenciado quanto às regras para elaboração do contrato de arrendamento de imóvel rural por estrangeiro quando o mesmo for firmado exclusivamente para a exploração de energia eólica, pois não fazer isso, consequentemente, afeta o meio ambiente, a ordem econômica, a geração de emprego e a circulação de riquezas. 
Nesse particular, importante mencionar que a desburocratização é um fenômeno que não tem mais volta, assim, atrelar o arrendamento de imóvel rural por estrangeiro para fins de exploração de energia eólica às regras comuns é nada mais do que burocratizar a própria busca pelo meio ambiente ecologicamente equilibrado, a circulação de riquezas e a busca do pleno emprego.

Essa normativa gera um efeito cascata demasiadamente negativo, pois a sua imposição onera desnecessariamente o procedimento já burocrático para a exploração de energia eólica por parte de pessoas estrangeiras no Brasil, desestimula investimentos e a sua implementação, limita o desenvolvimento de determinada região, freia a circulação de riquezas, causando danos à função social da propriedade, na defesa do meio ambiente, no auxílio à redução de desigualdades sociais e na busca pelo pleno emprego, princípios constitucionais da atividade econômica, afetando, por fim, até mesmo quem supostamente iria se beneficiar de tal norma legislativa, que são os Tabelionatos de Notas, que têm competência para lavrar escrituras públicas, pois, o empobrecimento de todos os fatores acima mencionados contribui para a falta de circulação econômica na própria região desse cartório, ocasionando na queda de atos praticados.

Por fim, deve-se refletir sobre a modificação do entendimento normativo para que, em respeito aos direitos e garantias constitucionais do meio ambiente ecologicamente equilibrado, da circulação de riquezas, da geração de emprego e manutenção da ordem econômica, nos contratos para arrendamento de imóveis rurais para exploração de energia eólica, quer sejam firmados por empresas com capital exclusivamente nacional ou não, não sejam impostas as regras do $\operatorname{art}^{\circ} .23$ da Lei 8.629/93.

Data de Submissão: 06/08/2019

Data de Aprovação: 20/11/2020

Processo de Avaliação: double blind peer review 
Os Contratos De Arrendamento De Imóveis Rurais Para A Exploração De...

Editor Geral: Jailton Macena de Araújo

Editor de Área: Fernando Joaquim Ferreira Maia

Assistente Editorial: Igor Barbosa Beserra Gonçalves Maciel

\section{REFERÊNCIAS}

ALMEIDA, Patrícia José de; BUAINAIN, Antônio Márcio. Os contratos de arrendamento e parceria no Brasil. In: Revista Direito GV, São Paulo, v. 9, n. 1, p. 319-344, jan./jun. 2013.

ARAÚJO, Amanda Alves; MOURA, Geraldo Jorge Barbosa de. A literatura científica sobre os impactos causados pela instalação de parques eólicos: análise cienciométrica. In: Revista Tecnologia e Sociedade, Curitiba, v. 13, n. 28, p. 207-223, mai./ago. 2017.

BAHIA (Estado). Provimento Conjunto CGJ/CCI no oo1/2018, de 25 de janeiro de 2018: Código de Normas e Procedimentos dos Serviços Notariais e de Registro do Estado da Bahia. Salvador, BA, [2019]. Disponível em: http://www5.tjba.jus.br/extrajudicial/wpcontent/uploads/2018/o9/codigo-de-normas.pdf. Acesso em: 04 de jul. 2019.

BAHIA (Estado). Secretaria de Planejamento do Governo do Estado da Bahia. Bahia é o primeiro em energia eólica no país. Disponível em: http://www.seplan.ba.gov.br/2019/o4/799/Bahia-eo-primeiro-em-energia-eolica-no-pais.html. Acesso em: o5 de jun. 2017.

\section{BRASIL. ABEEólica - Associação Brasileira de Energia}

Eólica. São Paulo, SP, 2018. Disponível em:

https://mailchi.mp/infographya/anoreg-news-edio-n-30-jul2018 . Acesso em: 09 jun. 2019.

BRASIL. [Constituição (1988)]. Constituição da República Federativa do Brasil de 5 de outubro de 1988. Brasília, DF: Presidência da República, [2017]. Disponível em:

http://www.planalto.gov.br/ccivil_03/constituicao/constituicaocom pilado.htm. Acesso em: 16 jun. 2019.

BRASIL. Lei no $5 \cdot 709$, de 7 de outubro de 1971. Regula a Aquisição de Imóvel Rural por Estrangeiro Residente no País ou 
Pessoa Jurídica Estrangeira Autorizada a Funcionar no Brasil, e dá outras Providências. Brasília, DF: Presidência da República, [1993]. Disponível em:

http://www.planalto.gov.br/ccivil_03/leis/L5709.htm. Acesso em: 04 jun. 2019.

BRASIL. Lei no 6.015, de 31 de dezembro de 1973. Dispõe sobre os registros públicos, e dá outras providências. Brasília, DF:

Presidência da República, [2019]. Disponível em:

http://www.planalto.gov.br/ccivil_03/leis/L6015compilada.htm. Acesso em: 05 jun. 2019.

BRASIL. Lei no 8.629, de 25 de fevereiro de 1993. Dispõe sobre a regulamentação dos dispositivos constitucionais relativos à reforma agrária, previstos no Capítulo III, Título VII, da Constituição Federal. Brasília, DF: Presidência da República, [2017]. Disponível em: http://www.planalto.gov.br/ccivil_03/leis/18629.htm. Acesso em: 02 jun. 2019.

BRASIL. Projeto de Lei da Câmara dos Deputados $n^{\circ} \mathbf{3 . 8 9 9}$, de 22 de maio de 2012. Brasília, DF: Câmara dos Deputados, 2012. Disponível em:

https://www.camara.leg.br/proposicoesWeb/fichadetramitacao?idPr oposicao $=545304$. Acesso em: 11 jun. 2019.

\section{BRASIL. Projeto de Lei do Senado no 484, de o6 de}

dezembro de 2017. Brasília, DF: Senado Federal, 2017. Disponível em: https://www25.senado.leg.br/web/atividade/materias//materia/131829. Acesso em: 11 jun. 2019.

BRASIL. Provimento no 43, de 17 de abril de 2015. Dispõe sobre o arrendamento de imóvel rural por estrangeiro residente ou autorizado a funcionar no Brasil, bem como por pessoa jurídica brasileira da qual participe, a qualquer título, pessoa estrangeira física ou jurídica que resida ou tenha sede no exterior e possua a maioria do capital social. Brasília, DF: Conselho Nacional de Justiça, [2015]. Disponível em: http://www.cnj.jus.br/busca-atosadm?documento=2935. Acesso em: o5 jul. 2019.

BRASIL. Provimento no 6o, de 10 de agosto de 2017.

Estabelece diretrizes gerais para a cobrança de emolumentos sobre os contratos de exploração de energia eólica. Brasília, DF: Conselho Nacional de Justiça, [2017]. Disponível em:

http://www.cnj.jus.br/busca-atos-adm?documento=3355. Acesso em: 05 jul. 2019.

FEARNSIDE, Philip; MILLIKAN, Brent. Hidrelétricas na Amazônia: Fonte de energia limpa? pp. 47-54; In: O Setor Elétrico

Brasileiro e a Sustentabilidade no Século 21: Oportunidades e Desafios. 2. ed. Brasília, DF: Rios Internacionais, nov. 2012. 
Os Contratos De Arrendamento De Imóveis Rurais Para A Exploração De...

FEIJÓ, Juliane Holder Câmara Silva. Empreendimentos Energéticos em Terras Indígenas: Uma Análise Constitucional à Luz do Multiculturalismo. In: Argumentun, Marília, n. 15, p. 47-72, jan./dez. 2014.

FERREIRA, Leandro José; GOMES, Magno Federici. A Teoria Neoconstitucionalista do Processo e a Possibilidade de Concessão de Tutela Provisória Liminar para a Proteção do Direito Fundamental ao Meio Ambiente. In: Argumentun, Marília, v. 18, n. 3, p. 625-643, set./dez. 2017.

GOMES, Luiz Eduardo Bueno; HENKES, Jairo Afonso. Análise da Energia Eólica no Cenário Elétrico: Aspectos Gerais e Indicadores de Viabilidade Econômica. In: Revista Gestão e Sustentabilidade Ambiental. Florianópolis, v. 3, n. 2, p. 463-482, out. 2014/mar. 2015 .

GOVERNO DO BRASIL. Fontes hidráulicas geram a maior parte da energia elétrica. Disponível em:

http://www.brasil.gov.br/noticias/infraestrutura/2011/12/fonteshidraulicas-geram-a-maior-parte-da-energia-eletrica. Acesso em: 03 de jul. 2019.

LASBIK, Thaís Aldred; GOMES, Magno Federici. A mineração sustentável como fator essencial à promoção da dignidade e dos Direitos Humanos. In: Revista Prim@ Facie, João Pessoa, v. 17, n. 36, p. 1-29. 2018. Disponível em:

https://periodicos.ufpb.br/index.php/primafacie/article/view/3838 4/21393. Acesso em: 29 de dez. 2019.

LOUREIRO, Luiz Guilherme. Registros Públicos: Teoria e Prática. 9. ed. Salvador: Juspodivm, 2018.

MAIA, Joaquim Fernando Ferreira; SILVA, Rafaela Patrícia Inocêncio da. A extrafiscalidade como instrumento de controle do impacto ambiental gerado pelos resíduos sólidos diante da globalização do mercado. In: Revista Pensar, Fortaleza, v. 23, n. 3, p. 1-13, jul./set. 2018. Disponível em:

https://periodicos.unifor.br/rpen/article/view/6453/pdf. Acesso em: 20 de jul. 2019.

MAIDANA, Ana Paula Duarte Ferreira; BOGGI, Cassandra Libel Esteves Barbosa. Descarbonização: Relevância Ambiental e Aspectos Tributários. In: Revista Argumentun, Marília, v. 10, p. 179-197, jan./dez. 2009.

MATO GROSSO DO SUL (Estado). Provimento CGJ no 001/2013, de 27 de janeiro de 2013: Dispõe sobre a atualização do Código de Normas da Corregedoria-Geral de Justiça e dá outras 
providências. Campo Grande, MS, [2019]. Disponível em:

http://corregedoria.tjrn.jus.br/index.php/normas/codigos/codigode-normas-extrajudicial/10481--1103/file. Acesso em: 05 de jul. 2019.

MINAS GERAIS (Estado). Provimento no 250/CGJ/2013, de 29 de outubro de 2013: Codifica os atos normativos da CorregedoriaGeral de Justiça do Estado de Minas Gerais relativos aos serviços notariais e de registro. Belo Horizonte, MG, [2019]. Disponível em: http://www8.tjmg.jus.br/institucional/at/pdf/cpro2602013.pdf . Acesso em: 05 de jul. 2019.

PAYÃO, Jordana Viana; VITA, Jonathan Barros. Desafios Regulatórios do Caso Airbnb: a Intervenção do Estado no Modelo Econômico Colaborativo. In: Revista Justiça do Direito, Passo Fundo, v. 32, n. 1, p. 203-230, jan./abr. 2018.

PROLO, Caroline Dihl; SARAGOÇA, Mariana; OLIVEIRA, Tábata Boccanera Guerra de; NUNES, Guilherme; SOUZA, Letícia Beatriz de Oliveira de. Legislação e papel das energias renováveis no Brasil. JOTA, 22. out. 2018. Disponível em: https://www.jota.info/opiniao-e-analise/artigos/legislacao-e-papeldas-energias-renovaveis-no-brasil-22102018. Acesso em 05 de jul. 2019.

RIO GRANDE DO NORTE (Estado). Provimento CGJ no 156/2016, de 18 de outubro de 2016: Institui no Âmbito Extrajudicial o Novo Código de Normas da Corregedoria Geral de Justiça do Estado do Rio Grande do Norte. Natal, RN, [2019]. Disponível em: http://corregedoria.tjrn.jus.br/index.php/normas/codigos/codigode-normas-extrajudicial/10481--1103/file. Acesso em: 05 de jul. 2019.

RIO GRANDE DO SUL (Estado). Provimento no o32/2006-CGJ, de 16 de novembro de 2006: Institui a Consolidação Normativa Notarial e Registral do Estado do Rio Grande do Sul. Porto Alegre, RS, [2019]. Disponível em: https://www.tjrs.jus.br/export/legislacao/estadual/doc/2019/CNNR _CGJ_Junho_2019_Provimento_016_2019.pdf. Acesso em: 05 de jul. 2019.

RONDÔNIA (Estado). Provimento no o18/2015-CG, de 16 de setembro de 2015: Diretrizes Gerais Extrajudiciais do Estado de Rondônia. Porto Velho, RO, [2019]. Disponível em: https://www.tjro.jus.br/corregedoria/images/Diretrizes_Gerais_Ext rajudiciais_-_Atualizada_em_11-02-19.pdf. Acesso em: 04 de jul. 2019.

SANTOS, Thiago Flores dos; FREITAS, Carla Pinheiro. Logística 
Os Contratos De Arrendamento De Imóveis Rurais Para A Exploração De...

reversa como instrumento essencial à efetivação da responsabilidade ambiental empresarial. In: Revista Prim@ Facie, v. 16, n. 32, p. 135. 2017. Disponível em:

https://periodicos.ufpb.br/index.php/primafacie/article/view/34157 /17961. Acesso em: o1 de dez. 2019.

SÃO PAUlO (Estado). Decreto Estadual de São Paulo no 58.107, de 05 de junho de 2012. Institui a Estratégia para o Desenvolvimento Sustentável do Estado de São Paulo 2020, e dá providências correlatas. São Paulo, SP, [2012]. Disponível em: http://www.legislacao.sp.gov.br/legislacao/dg280202.nsf/5fb5269e d17b47ab83256cfboo501469/1108b39f578a143383257a15004cboc4 ?OpenDocument. Acesso em: 10 jun. 2019.

SÃO PAUlO (Estado). Provimento no o58/1989-CGJ, Tomo II, de 28 de novembro de 1989: Institui as Normas de Serviço dos Cartórios Extrajudiciais do Estado de São Paulo. São Paulo, SP, [2019]. Disponível em:

https://api.tjsp.jus.br/Handlers/Handler/FileFetch.ashx?codigo=112 823. Acesso em: o5 de jul. 2019.

SERRA, Márcio Guerra; SERRA, Monete Hipólito. Registro de Imóveis I: Parte Geral. In: CASSETTARI, Christiano (coord). Coleção Cartórios. São Paulo: Saraiva, 2013.

SILVA, Alexander Marques; VIEIRA, Rogério Márcio Fonseca. Energia eólica: conceitos e características basilares para uma possível suplementação da matriz energética brasileira. In: Revista Direito Ambiental e sociedade, Caxias do Sul, v. 6, n. 2, p. 53-76. 2016.

UFJF. Hidrelétricas na Amazônia podem emitir mais gases de efeito estufa que usinas a carvão, óleo e gás. Disponível em: https://www2.ufjf.br/noticias/2016/o1/28/hidreletricas-naamazonia-podem-emitir-mais-gases-de-efeito-estufa-que-usinas-acarvao-oleo-e-gas/. Acesso em: 03 de jul. 2019.

VIOMUNDO: Diário da Resistência. Célio Bermann e Belo Monte: "A energia hidrelétrica não é limpa, nem barata”. Disponível em: https://www.viomundo.com.br/retratos/bermann-a-energiahidreletrica-nao-e-limpa-nem-barata.html. Acesso em: 04 de jul. 2019. 


\title{
Rural Property Lease Contracts For Wind Energy Exploitation By Foreign Capital Companies And The Enforcement Of Standards Affecting The National Economic Order
}

\section{Bruno Bastos de Oliveira}

\author{
Fellipe Vilas Bôas Fraga
}

\begin{abstract}
The scope of this article is to analyze the issues involving wind energy exploitation in rural properties by companies with foreign capital percentage, whose contracts are signed under lease. As most companies that invest in wind energy in Brazil have part of foreign capital, the legal determinations lead to the application of rules that make the exploitation of this clean technology more expensive, often removing investments and even making this branch of the energy sector unfeasible, consequently affecting the sustainable national development, the social economic order and the preservation of the environment. The aim is to analyze the need to change the rules for the lease of rural properties for wind energy exploitation by legal entities with foreign capital. As methodology, the deductive method will be used, through bibliographic and legislative research. It is concluded that there is a need to change the normative understanding, so that the rules of art. 23 of Law 8.629/93 are not imposed in the lease agreements of rural properties for wind energy exploration, whether they are signed by companies with exclusively national capital or not.
\end{abstract}

Keywords: Clean Technologies. Wind Energy. Lease. Foreign Capital. Sustainable Development. 